\title{
Carbon emission imbalances and the structural paths of Chinese
}

\section{regions}

Ling Shao ${ }^{a, b, c, *}$, Yuan Li ${ }^{d, c, *}$, Kuishuang Feng ${ }^{e}$, Jing Meng ${ }^{f}$, Yuli Shan ${ }^{c}$, Dabo Guan ${ }^{c}$

${ }^{a}$ School of Humanities and Economic Management, China University of Geosciences, Beijing 100083, China

${ }^{\mathrm{b}}$ Key Laboratory of Carrying Capacity Assessment for Resource and Environment, Ministry of Land and Resource, Beijing 100083, China

${ }^{\mathrm{c}}$ Tyndall Centre for Climate Change Research, School of International Development, University of East Anglia, Norwich, NR4 7TJ, UK

${ }^{\mathrm{d}}$ Institute of Resource, Environment and Sustainable Development, Jinan University, Guangzhou 510632, China

${ }^{\text {e }}$ Department of Geographical Sciences, University of Maryland, College Park, MD 20742, USA

${ }^{\mathrm{f}}$ Department of Politics and International Studies, University of Cambridge, Cambridge CB3 9DT, UK

\section{Abstract}

As the Chinese regions become more and more connected to each other and foreign countries, this study aims to address carbon imbalance and outsourcing issues in China. Using a production-based carbon emission inventory and a China-global multiregional input-output model, this study estimates the consumption-based carbon emissions in 30 Chinese regions in 2007 and 2010. Our results reveal that the carbon imbalances of most Chinese provinces and cities have decreased between 2007 and 2010, but disparities in the regional per capita carbon footprint have widened. Our applying Structural Path Analysis (SPA) shows that most Chinese regions have higher

\footnotetext{
${ }^{*}$ Corresponding authors. Tel.: +86010 82322078; Fax: +86010 82321783.

E-mail addresses: lingshao@pku.edu.cn, shaoling@cugb.edu.cn (Ling Shao); y.li4@uea.ac.uk (Yuan Li).
} 
ratios of both imported (to consumption-based) and exported (to production-based) carbon emissions in further upstream supplier tiers than that of direct imports and exports in the first tier, thus it's vital to trace emissions in the upstream supply chain to understand emission outsourcing. Our result from four case study provinces suggests that Beijing should import more electricity products from nearby Hebei and Shandong rather than Inner Mongolia to lower its consumption-based carbon emissions given the smaller emission coefficients of their electricity production.

\section{Keywords}

Production-based carbon emissions; Consumption-based carbon emissions; Multiregional input-output analysis; Carbon emission imbalance; Structural path analysis; Carbon emission pathways

\section{Introduction}

At the Paris climate conference (COP21) in December 2015, 195 countries adopted the Paris Agreement within the framework of the United Nations Framework Convention on Climate Change (UNFCCC). It is generally considered to be the historic turning point for reducing global warming [1]. Prior to and during the Paris conference, some countries submitted Intended Nationally Determined Contributions (INDCs), which represented the targets that each country should reach in order to achieve the global goal. As early as June 2015, China announced its INDCs and committed to the achievement of peak carbon dioxide emissions around 2030 and the 
reduction of carbon dioxide emissions per unit of GDP by $60 \%$ to $65 \%$ from 2005 levels by $2030[2]$.

The ambitious climate mitigation goal of China can be achieved through regionlevel efforts. China has initiated low-carbon development pilots in 6 provinces and 36 cities, which include $42 \%$ of the total population, $57 \%$ of the GDP, and $56 \%$ of all carbon emissions [2]. In addition, the second session of the China-U.S. ClimateSmart/Low-Carbon Cities Summit was held in Beijing in June 2016 and was attended by participants from 17 U.S. cities, counties, and states and from 49 Chinese cities and provinces. The participating Chinese provinces and cities intend to perform enhanced actions to support the achievement and implementation of China's respective post-2020 national climate targets. During the Summit, the NDRC (National Development and Reform Commission) of China announced that the number of low-carbon development pilot cities in China will increase to 100 [3].

The newly launched $13^{\text {th }}$ Five Year Plan (2015-2020) reported that China achieved a $20 \%$ reduction, which more than satisfied the $17 \%$ carbon intensity reduction goal proposed in the $12^{\text {th }}$ Five Year Plan (2010-2015), and determined a new $18 \%$ mandatory goal for the next five years [4]. Each Chinese province was allocated mandatory energy reduction and carbon emission mitigation targets (see Supporting Information, i.e., SI, Table S1), which was slightly higher than that in the previous plan $[5,6]$. Annual achievement of the reduction of emission intensity by each local government was assessed by the central government as an important performance evaluation indicator. According to the report, the most rapidly developing provinces 
or cities, e.g., Beijing and Shanghai, easily achieved the goal, while a few lessdeveloped provinces, e.g., Xinjiang and Qinghai, struggled to meet the requirement $[7,8]$.

The mandatory goal for each province during the $13^{\text {th }}$ Five Year Plan has been set according to its development stage, resources endowment, strategic position, ecoenvironmental protection, and so on [6]. In the future, scientific and accurate carbon emission data of Chinese regions need also to be taken into consideration to fairly attribute carbon emission reduction goal and efficiently achieve the INDC. The territorial emission inventory under UNFCCC plays a key role in current carbon emission management $[9,10]$. However, in recent years the growing inter-provincial trading led to more and more carbon transfer and imbalance issues in China [11-14]. For example, it is found that more than half of China's emissions are related to goods that are consumed outside of the province where they are produced in 2007 [15]. Therefore the consumption-based carbon emission inventory must be taken into consideration when properly identifying responsibility and assigning quotas [16]. Input-output analysis (IOA) has been frequently utilized to estimate consumptionbased carbon emission [17-20]. Among all the existing studies, the single-regional input-output (SRIO) analysis was applied to analyze GHG emissions of final demand in a national or regional economy [19-21] while the multi-regional input-output (MRIO) analysis was employed to calculate carbon emissions embodied in trade among different countries or regions [17, 18, 22-26]. According to IOA, all carbon emissions are driven by final demand, and thus, emissions associated with the 
production of goods and services are ultimately attributed to final consumption activities. Transmission chains from production-based carbon emission sources to consumption-based destinations can be very complex due to the deepening modern industry division, but they can be mathematically traced through production layers by the Structural Path Analysis (SPA) method [27-31]. A study by Liu et al. found that the huge emissions embodied in Chinese exports are in part due to the very high emissions intensity in a few provinces and industry sectors [32]. For a Chinese region, it would be also very important to uncover the key pathways that lead to its major carbon emissions, which can be identified by SPA. From the production perspective, a region may shut down its export supply chains, which drive the most carbon emissions, to lower its on-site carbon emissions. In contrast, from the consumption perspective, a region may choose to purchase alternative products that are produced with low carbon intensive technologies to reduce its carbon footprint.

Against this general background, this paper first accounts for and analyzes the consumption-based carbon emissions of 30 Chinese provinces and cities, based on which the carbon emission imbalance of each Chinese region is assessed. The results can assist policymakers in the task of properly allocating carbon emission mitigation targets among Chinese regions. This paper also demonstrates the methods of identifying key carbon emission structural paths of production-based and consumption-based carbon emissions from each province or city. It can provide assistance for designing efficient carbon emission reduction strategies for each region. 


\section{Methods and data}

\subsection{Methods}

2.1.1 Multi-regional input-output (MRIO) analysis

MRIO analysis has attracted widespread interest for addressing global environmental issues [33-35]. In an MRIO model, the same types of products developed from different economies are treated as entirely different products, and different regions are connected through an interregional trade matrix. With a given MRIO table, the total output vector $\mathbf{x}$ of the MRIO model, according to input-output theory $[36,37]$, is represented as

$$
\mathbf{x}=\mathbf{A} \mathbf{x}+\mathbf{y} \text { and } \mathbf{x}=(\mathbf{I}-\mathbf{A})^{-1} \mathbf{y}
$$

in which $\mathbf{A}$ is the technical coefficients matrix and $\mathbf{y}$ represents the final demand matrix. When subjected to Leontief's demand-pull model, the carbon emissions flow E driven by final demand can be calculated accordingly from

$$
E=\varepsilon x=\varepsilon(I-A)^{-1} y=m y,
$$

in which the vector $\boldsymbol{\varepsilon}$ represents the direct carbon emission coefficients, $\mathbf{I}$ is an identity matrix, and $\mathbf{m}=\boldsymbol{\varepsilon}(\mathbf{I}-\mathbf{A})^{-1}$ are designated as carbon emission multipliers [38] The emissions embodied in exports (EEE) and imports (EEI) can be then calculated from

$$
\mathrm{EEE}=\mathbf{m e} \text { and } \mathrm{EEI}=\mathbf{m i}
$$

where e and i represent the exports and imports matrices, respectively.

The indicator of per capita consumption-based carbon emissions, i.e., the carbon footprint, is used to evaluate the inequalities among different Chinese provinces and 
cities. In addition, an indicator of the CII (carbon emission imbalance index) is formulated in this work in order to assess the carbon emission trade imbalance of Chinese regions. For carbon emission net importers, this indicator is defined as the proportion of consumption-based carbon emissions that is net imported from other economies:

when $E_{\text {consumption }}>E_{\text {production, }} C I I=\left(E_{\text {consumption }}-E_{\text {production }}\right) / E_{\text {consumption. }}$

For carbon emission net exporters, it is defined as the proportion of production-based carbon emissions that is net exported to other economies:

$$
\text { when } E_{\text {consumption }}<E_{\text {production, }} C I I=\left(E_{\text {consumption }}-E_{\text {production }}\right) / E_{\text {production }} \text {. }
$$

It can be understood from the definition that a positive CII indicates that the economy leaks carbon emissions to other economies and a negative one indicates that the economy receives carbon leakage from other economies.

\subsubsection{Structural Path Analysis (SPA)}

The Leontief inverse (I-A) $\mathbf{~}^{\mathbf{1}}$ in Eq. (1) can be written as its Taylor expansion by using its power series approximation:

$$
(\mathbf{I}-\mathbf{A})^{-1}=\mathbf{I}+\mathbf{A}+\mathbf{A}^{2}+\mathbf{A}^{3}+\mathbf{L}
$$

Therefore, Eq. (2) can be expressed as

$$
\mathbf{E}=\boldsymbol{\varepsilon}(\mathbf{I}-\mathbf{A})^{-1} \mathbf{y}=\boldsymbol{\varepsilon} \mathbf{I} \mathbf{y}+\boldsymbol{\varepsilon} \mathbf{A} \mathbf{y}+\boldsymbol{\varepsilon} \mathbf{A}^{2} \mathbf{y}+\boldsymbol{\varepsilon} \mathbf{A}^{3} \mathbf{y}+\mathrm{L}
$$

where $\mathbf{A}^{t} \mathbf{y}$ represents the total intermediate product inputs at layer $t$ that are directly consumed by the preceding layer, i.e., layer $\mathrm{t}-1$, the sum of which is ultimately driven by final demand $\mathbf{y}$. Furthermore, $\mathbf{\varepsilon A}^{t} \mathbf{y}$ represents the total carbon emissions triggered 
by the production of these products. For example, if $\mathbf{y}$ represents a computer demand, then $\mathbf{E I y}$ in tier 0 (T0) represents the direct carbon emissions caused by the computer's production. In T1, Ay represents the intermediate inputs from other industries that are needed to produce the computer, e.g., the plastic and the screen, and $\mathbf{\varepsilon A y}$ indicates the carbon emissions emitted during the production of these inputs. This trace continues through the infinite production layers of the supply chain.

Eq. (7) can be further decomposed by unraveling the A matrix:

$$
\mathbf{E}=\sum_{\mathrm{i}, \mathrm{j}=1}^{\mathrm{n}} e_{i}\left(I_{i j}+a_{i j}+\sum_{\mathrm{k}=1}^{\mathrm{n}} a_{i k} a_{k j}+\sum_{\mathrm{l}=1}^{\mathrm{n}} \sum_{\mathrm{k}=1}^{\mathrm{n}} a_{i l} a_{l k} a_{k j}+\mathrm{L}\right) y_{j}
$$

where $e_{i}$ is the emission intensity or coefficient of industry $i, a_{i j}$ represents technical coefficients between sector $i$ and $j$, and $y_{j}$ represents the final demand bundle. Each multiplied term represents the contribution of an individual supply chain path. Both the total dispersion paths of produced pollution (production-based carbon emission) and carbon emissions supply paths driven by a given final demand (consumptionbased carbon emission) can be analyzed accordingly by Eq. (8).

In the present work, the detailed SPA results for all Chinese regions were very complex. To present a clear discussion, SPA results within each tier were aggregated into region-based emissions, which were further categorized into three sources or destinations: inner source, domestic import/export, and foreign import/export. The following symbols were applied to simplify the description: $\mathrm{E}_{\mathrm{p}} \mathrm{T} t$ (production-based carbon emissions from the $t^{\text {th }}$ tier); $\mathrm{E}_{\mathrm{c}}-\mathrm{T} t$ (consumption-based carbon emissions from the $t^{\text {th }}$ tier); $\mathrm{DEE}_{\mathrm{p}}-\mathrm{T} t$ (domestic exported carbon emissions from the $t^{\mathrm{h}}$ tier); $\mathrm{FEE}_{\mathrm{p}}-\mathrm{T} t$ (foreign exported carbon emissions from the $t^{\text {th }}$ tier); $\mathrm{EE}_{\mathrm{p}}-\mathrm{T} t$ (exported carbon 
emissions from the $t^{\text {th }}$ tier); $\mathrm{DIE}_{\mathrm{c}}-\mathrm{T} t$ (domestic imported carbon emissions from the $t^{\text {th }}$ tier); $\mathrm{FIE}_{\mathrm{c}}-\mathrm{T} t$ (foreign imported carbon emissions from the $t^{\text {th }}$ tier); and $\mathrm{IE}_{\mathrm{c}}-\mathrm{T} t$ (imported carbon emissions from the $t^{\text {th }}$ tier).

\subsection{Data sources}

We have chosen 2010 as the study year because it is the most recent year with available MRIO data of Chinese regions. Partial results of 2007 are also presented to detect the carbon emission evolvement trends. We referred to the multi-regional inputoutput table for 30 Chinese provinces and cities (C-MRIO) in 2007 and 2010 contributed by Liu and his colleagues [39]. It includes 22 provinces, 4 autonomous regions (excluding Tibet) and 4 municipalities (in total, 30 regions) of China. In our previous studies, we constructed the global MRIO (G-MRIO) tables for 2007 and 2011 [15], which are based on version 8 and version 9 of the Global Trade Analysis Project (GTAP) database [40, 41]. The GTAP has no data for 2010, and the G-MRIO table in 2011 was transferred to a table based in 2010 by using the average deflator index of each country [42]. To complete the system boundary, we connected the CMRIO model to G-MRIO tables to compile a China-global multi-regional inputoutput table (CG-MRIO).

The imports and exports in C-MRIO need to be disaggregated and allocated to 128 foreign countries. With reference to the previous study [15], we assumed that the international exports of each sector in C-MRIO were distributed among importing sectors in foreign countries in the same proportion as China's total exports in G- 
MRIO. We also made the converse assumption: each sector's international imports were sourced from foreign countries to each province in the same proportion as China's total imports in G-MRIO. The detailed inventory for Chinese and global regions and their respective production sectors can be found in Table S2, SI.

The $\mathrm{CO}_{2}$ emissions produced by fossil fuel combustion were estimated in this study using the method in the previous study [43]. Seventeen types of fossil fuels were considered. The fossil fuel energy consumption inventory was constructed from each sector's energy consumption data with reference to China's and each Chinese province's statistical yearbooks and to the China Economic Census Yearbook [44, 45]. The energy balance data were referred to exclude the fossil fuel loss in transportation and transmission, and non-energy use of fossil fuel as raw material. The combustionbased carbon emissions were then calculated from the new measured carbon emission factors of China [46].

According to the features of each province's carbon emission imports and exports and simultaneously taking geographical position into consideration, 30 Chinese provinces and cities were further categorized into 6 groups to present improved results. These groups are the Beijing-Shanghai-Tianjin region (Beijing, Shanghai, Tianjin), the North region (Hebei, Shanxi, Inner Mongolia, Liaoning, Jilin, Heilongjiang), the Coast region (Zhejiang, Jiangsu, Fujian, Shandong, Guangdong), the Central region (Anhui, Jiangxi, Henan, Hubei, Hunan, Guangxi), the Hainan and Southwest region (Hainan, Chongqing, Sichuan, Guizhou, Yunnan; hereinafter referred to as Southwest for simplicity), and the Northwest region (Shaanxi, Gansu, 
Qinghai, Ningxia, Xinjiang). The classification method was slightly different from that in previous studies $[15,47]$, and the geographical positions of a few provinces did not quite fit the region to which they belong. However, this method was used to better capture the carbon emission features of Chinese regions at different development levels and to advance relevant policy suggestions at a manageable level.

\section{Results and discussions}

\subsection{Production-based and consumption-based carbon emissions}

Production-based carbon emissions of China have increased by $16 \%$ (from 5,454 $\mathrm{Mt} \mathrm{CO}_{2}$ in 2007 to $6,347 \mathrm{Mt} \mathrm{CO}_{2}$ in 2010), while consumption-based carbon emissions (from 4,430 $\mathrm{Mt} \mathrm{CO}_{2}$ in 2007 to 5,708 $\mathrm{Mt} \mathrm{CO}_{2}$ in 2010) have increased twice as fast as production-based emissions. Although China was still classified as a carbon emission net exporter, the net carbon emission export significantly declined by $38 \%$ from 2007 to 2010 . This decrease may be due to the increased import of goods and services driven by the improved living standards in China and by changes in lifestyle and consumption patterns and may also be caused by the concurrent decreased amount of Chinese export since the 2008 global financial crisis.

The production-based and consumption-based carbon emissions of 30 Chinese provinces and cities are illustrated in Figure 1. Nearly all production-based and consumption-based carbon emissions from the provinces and cities have increased between 2007 and 2010, and the latter has increased faster than the former for most regions. Some northern and northwestern provinces, i.e., Inner Mongolia, Shaanxi and 
Ningxia, experienced the largest growths in both production-based and consumptionbased carbon emissions due to the rapid development of these less-developed regions. By contrast, the consumption-based carbon emissions of a few central, southern and southwestern provinces and cities, e.g., Anhui, Jiangxi, Hubei, Hainan, Chongqing and Sichuan, lagged behind the increase in production-based carbon emissions, which indicated that a significant portion of their direct emissions growth was driven by the final consumption of other regions. It can be noted that the less-developed Chinese regions have great carbon emissions growth potential, and the northern regions of China have developed slightly faster compared to the southern regions.

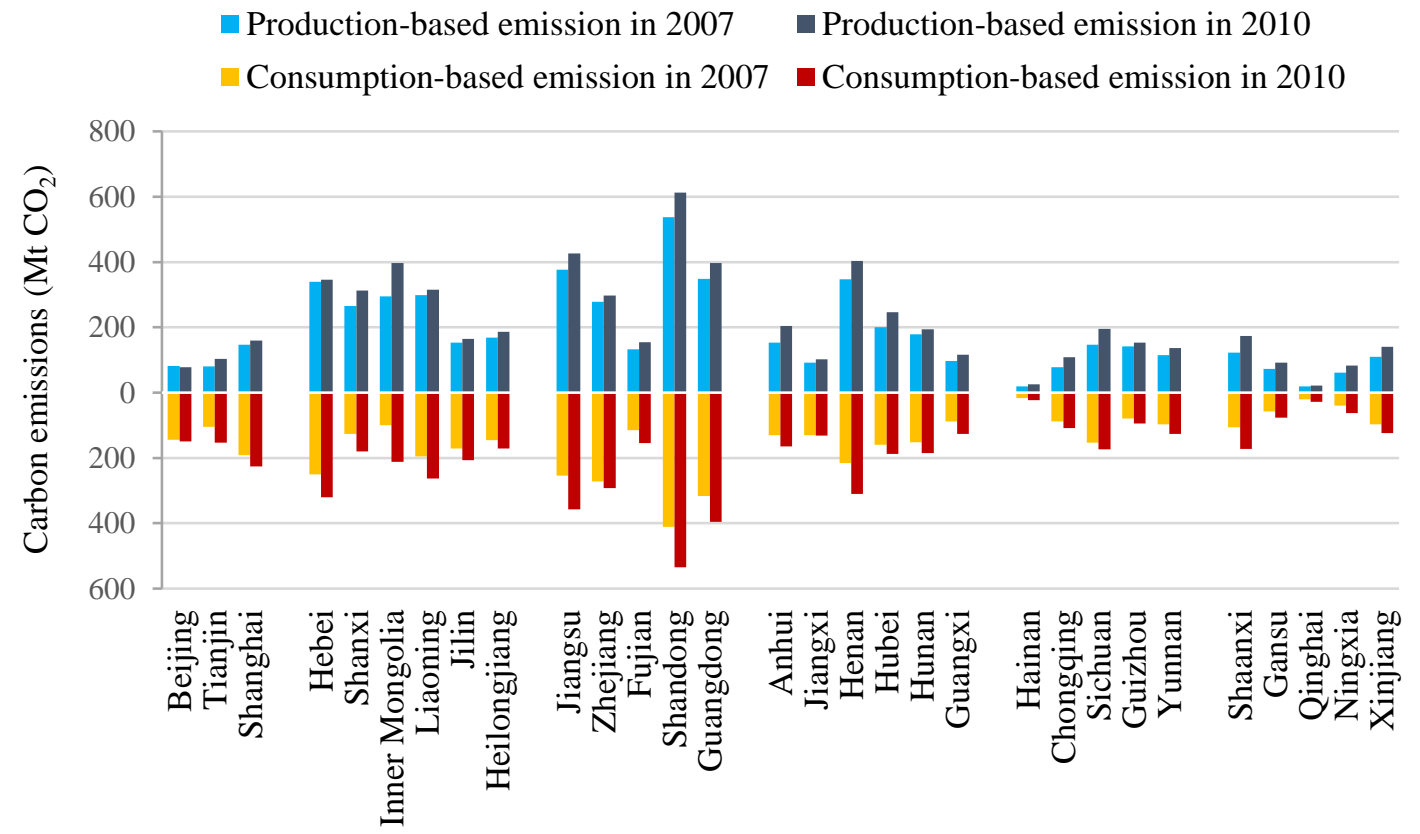

Figure 1. Production-based and consumption-based carbon emissions in 2007 and 2010

\subsection{Carbon emissions embodied in trade}

The carbon emissions embodied in both the domestic and foreign trades of 30 
Chinese provinces and cities are calculated (see Figure 2; the results for 2007 can be found in Figure S1, SI). In general, the carbon emissions embodied in domestic trade have increased by $16 \%$ from $1,924 \mathrm{Mt} \mathrm{CO}_{2}$ to $2,240 \mathrm{Mt} \mathrm{CO}_{2}$, which shows a synchronous development with production-based carbon emissions. However, the carbon emissions embodied in foreign trades followed a different pattern. The foreign exported carbon emissions have declined by $17 \%$ in the study period as a result of the international economic crisis that started in 2008. However, foreign imported carbon emissions have increased by $52 \%$ due to increases in government-led capital investment and household consumption. Although the carbon emissions embodied in foreign imports grew quickly, they only amounted to approximately two fifths of that embodied in foreign exports in 2010. This comparison indicates that China still has a long way to go before it reaches the international carbon emission balance.

Most Chinese provinces and cities exhibited significant increases in domestic exported, domestic imported, and foreign imported carbon emissions, while most provinces and cities experienced decreases in foreign exported carbon emissions. Jiangxi and Sichuan had the fastest growing domestic exported carbon emissions and also showed an unusual increase in foreign exported carbon emissions. Meanwhile, their foreign imported carbon emissions doubled from 2007 to 2010. Chongqing showed the same trend as Jiangxi and Sichuan. Beijing and Shanghai, as internationalized megacities, had the largest decline in foreign exported carbon emissions. Compared to all other Chinese provinces and cities, the domestic and foreign imported carbon emissions of Inner Mongolia both increased at the fastest 
pace. This rapid increase served as an important contribution to its nearly doubled consumption-based carbon emissions.

The changes in the carbon emissions trade structure were joint results of the global financial crisis and China's domestic industry transfer. On the one hand, developed Chinese provinces on the east coast and megacities rely more on foreign trade compared to less-developed central and western regions, whose international exports have been hit hard since the 2008 global financial crisis. In contrast, the foreign trades of the relatively less affected central and western regions increased quickly from very low baselines. On the other hand, due to the rising cost of labor and other production means and the growing desire for a clean environment by increasingly affluent residents, the eastern coastal regions transferred many labor-intensive manufacturing industries to the central and western regions. This process has spurred rapid increases of external trades in less-developed Chinese regions.

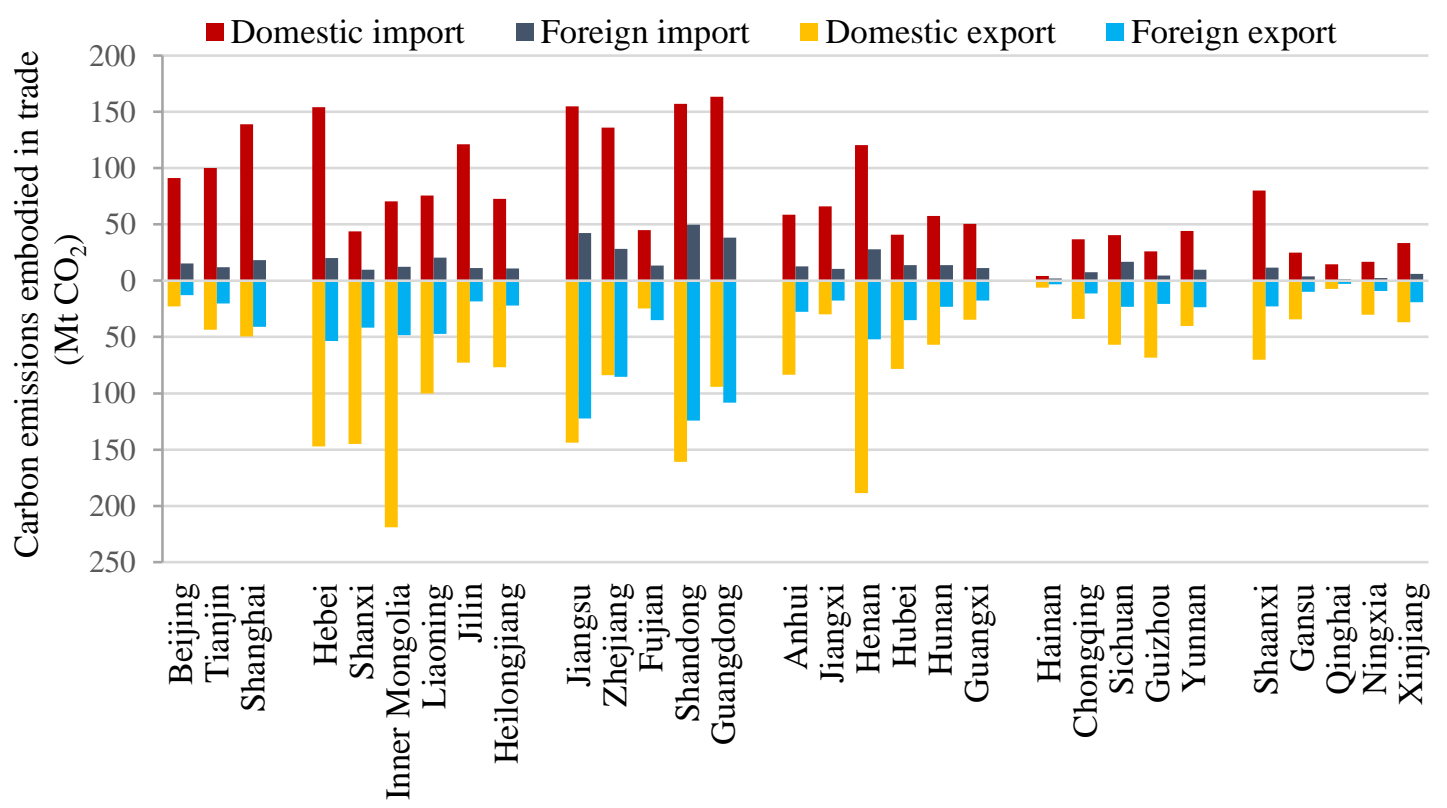


Figure 2. Carbon emissions embodied in trade in 2010

\subsection{Carbon emission imbalance and per capita consumption-based carbon} emissions

The CIIs, as defined in Section 2, of 30 Chinese provinces and cities and of a few foreign countries in 2010 are shown in Figure 3 (the abbreviations are explained in SI, Table S2). Only seven Chinese provinces and cities had positive CII values in 2010, and Beijing, Tianjin, and Shanghai, as three municipalities, had the largest CIIs. By contrast, Inner Mongolia, Shanxi, and Guizhou, as northern and southern provinces, experienced the lowest CIIs due to the large net export of emission intensive goods to other regions or countries. Although most of the Chinese provinces and cities were still net carbon emission exporters in 2010, the carbon emission imbalances for most Chinese provinces and cities decreased during the study period (the CII results for 2007 can be found in Figure S2, SI). The CII for China as a whole in 2010 was -0.10 , which indicated that the net export carbon emissions accounted for $10 \%$ of the total production-based carbon emissions. This value was only half that in 2007.

In 2010, Sichuan's average carbon footprint was as low as $2.15 \mathrm{t} \mathrm{CO}_{2} /$ capita, which was only one fifth that in Tianjin. Nearly all Chinese provinces and cities exhibited increases in their per capita carbon footprints from 2007 to 2010. As a result, the per capita carbon emission of China as a whole increased from 3.42 to $4.29 \mathrm{t} \mathrm{CO}_{2}$, which began to surpass the global average in $2010\left(3.50 \mathrm{t} \mathrm{CO}_{2}\right)$. However, despite this increase, the variance among per capita carbon emissions from Chinese provinces and cities in 2010 was $23 \%$ higher than that in 2007. 
Overall, the carbon emission imbalances of most Chinese regions, as well as China as a whole, have been reduced, but regional disparities have widened between 2007 and 2010. The CII and per capita consumption-based carbon emission can aid in the balancing of fairness and efficiency when assigning carbon emission reduction goals to Chinese regions. Those regions with the lowest CIIs, e.g., Inner Mongolia and Shanxi, should set slightly lower goals than the other regions because large portions of their production-based carbon emissions have been driven by the final consumption of other places. When geographical conditions were equal, regions with relatively low per capita consumption-based carbon emissions were less responsible than other regions. These regions should be allocated smaller carbon emission reduction quotas. For example, as both northeastern provinces, Heilongjiang should be given a smaller carbon emission reduction goal than Jilin.

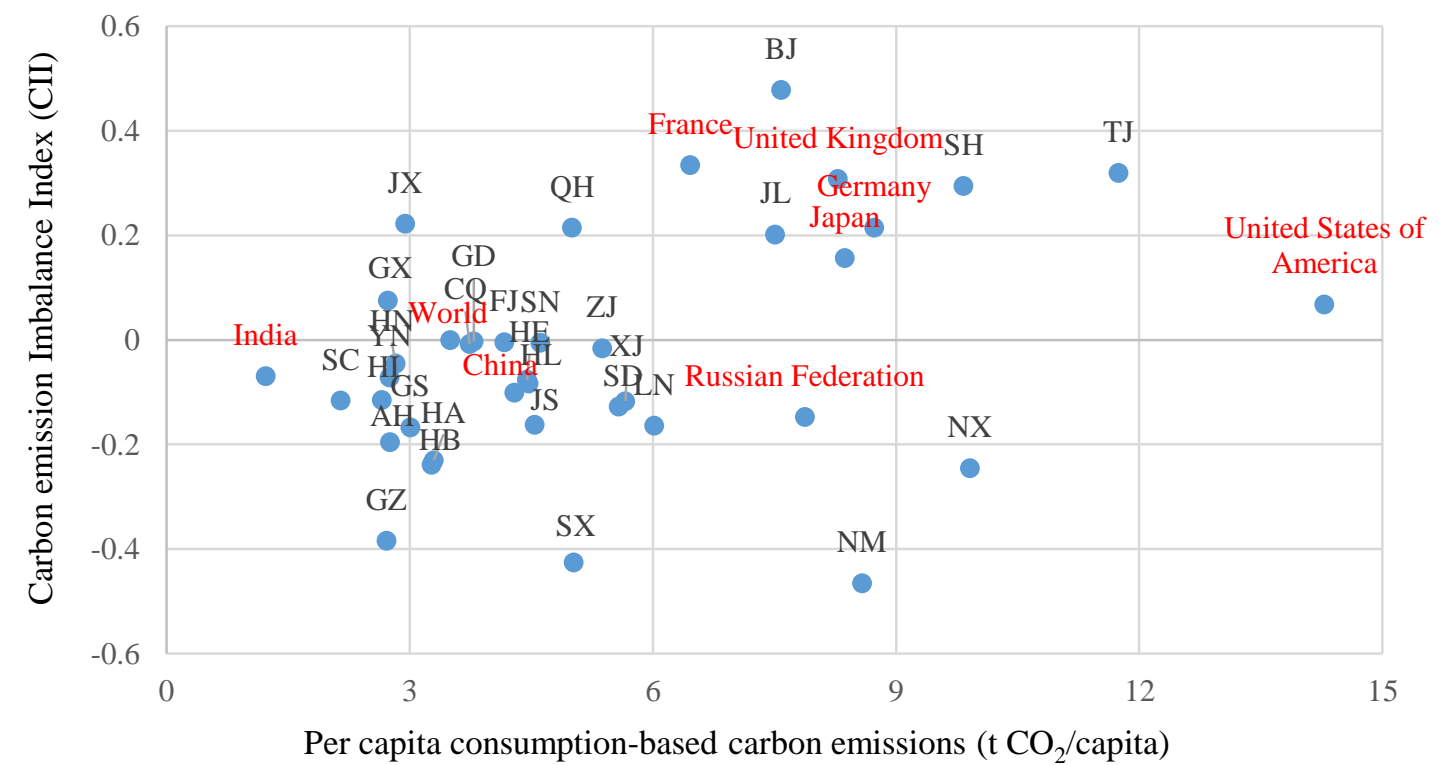

Figure 3. CII and per capita consumption-based carbon emissions in 2010 


\subsection{Production-based and consumption-based carbon emissions in different tiers}

An SPA analysis for the carbon emissions from 30 Chinese provinces and cities in 2010 is carried out to further uncover the transmission mechanism of productionbased to consumption-based carbon emissions. Six tiers from T0-T5 are traced, covering $89 \%$ and $91 \%$ of China's total production-based and consumption-based carbon emissions, respectively.

Figure 4 shows the production-based carbon emissions of 30 Chinese provinces and cities in different tiers. In 2010, most regions embodied the largest production-based carbon emissions in T1, while the carbon emissions embodied in T0 from Shanghai and Xinjiang and in T2 from Jiangxi, Inner Mongolia, Jiangsu, and Ningxia ranked as the largest of all tiers. In general, regions with relatively lower ratios of $\mathrm{E}_{\mathrm{p}}$ - $\mathrm{T} 0$ to total

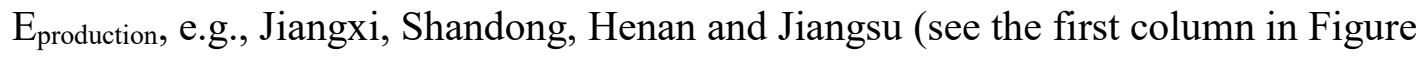
4), have embodied more production-based carbon emissions in their supply chains compared to other regions. To design efficient carbon emission reduction strategies, these regions may benefit from applying SPA as a method of identifying key carbon emission dispersion pathways occurring in higher tiers to reduce the territorial carbon emissions. Hebei and Shaanxi, with low $\mathrm{EE}_{\mathrm{p}}$ ratios in $\mathrm{T} 0(13 \%$ and $14 \%)$ but with high ratios of overall $\mathrm{EE}_{\mathrm{p}}$ to total $\mathrm{E}_{\text {production }}(58 \%$ and $54 \%$ ), should pay more attention to their exported carbon emission in higher tiers. This is because the apparent production-based carbon emissions transfer, indicated by the $\mathrm{EE}_{\mathrm{p}}$ ratio in $\mathrm{T} 0$, may mislead them on the major driving factors of their production-based carbon emissions. 


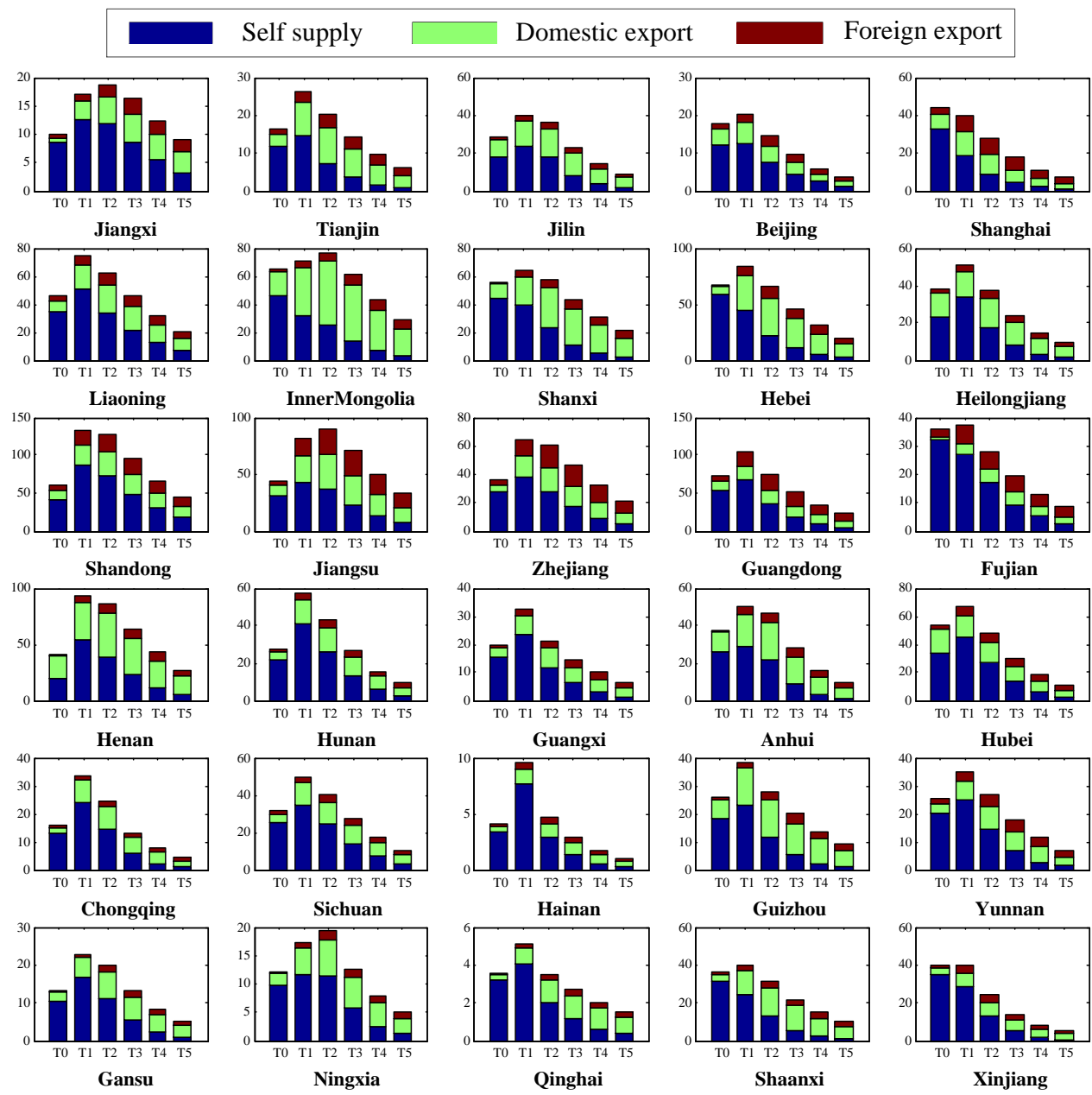

Figure 4. Production-based carbon emissions in different tiers (Unit: $\mathrm{Mt} \mathrm{CO}_{2}$ );

Each row of the figure represents a Chinese region. The North and Central regions each includes six provinces. To present an aligned picture, Jilin, a province belonging to the North region, and Jiangxi, belonging to the Central region, are moved to the second row, i.e., the Beijing-Shanghai-Tianjin region, due to their high dependencies on external sources. Five provinces or cities in a row are sorted by the proportion of carbon emissions in $\mathrm{T} 0$, i.e., $\mathrm{E}_{\mathrm{p}} \mathrm{T} 0$, relative to the total production-based carbon emissions. This indicates the transparency of carbon emissions transfer for a given demand; the higher the indicator is, the more apparent it is that carbon emissions in Tier 0 have been transferred.

Figure 5 shows the SPA results of 30 Chinese provinces and cities from a consumption perspective. In 2010, most regions embodied the largest consumption- 
based carbon emissions in T1, while carbon emissions embodied in $\mathrm{T} 0$ from Shanghai, Jiangxi, Inner Mongolia, Hebei, Fujian, and Xinjiang and in T2 from Beijing, Shandong, Jiangsu, and Ningxia were the largest of all tiers. The $\mathrm{E}_{\mathrm{c}}-\mathrm{T} 0$ to $\mathrm{E}_{\text {consumption }}$ ratios of Shandong, Henan, and Beijing (see the first column in Figure 5) were lower than that of the other regions. Because these regions have embodied higher unapparent consumption-based carbon emissions than the other regions, switching to low-carbon supply chains would be a beneficial choice for them to reduce their carbon footprint. Xinjiang, Shanxi and Anhui may underestimate their outsourced carbon emissions if they only consider the apparent carbon emission transfer in $\mathrm{T} 0$. Their $\mathrm{IE}_{\mathrm{c}}-\mathrm{T} 0$ to $\mathrm{E}_{\mathrm{c}}-\mathrm{T} 0$ ratios were only $5 \%, 6 \%$, and $8 \%$, respectively. However, they outsourced $32 \%, 30 \%$, and $44 \%$ of their total $\mathrm{E}_{\text {consumption, respectively. }}$ 


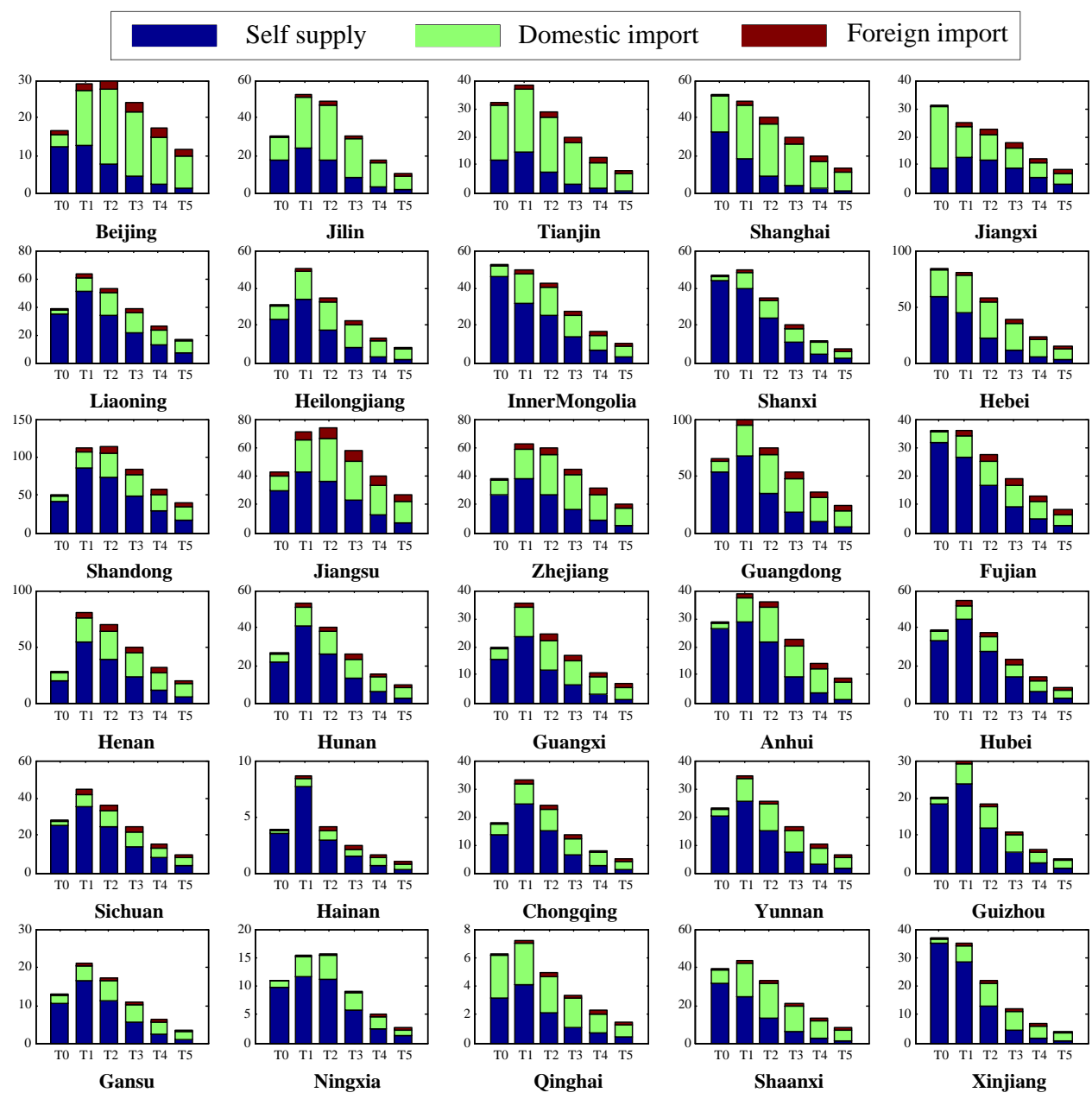

Figure 5. Consumption-based carbon emissions in different tiers (Unit: $\mathrm{Mt}$

$\mathrm{CO}_{2}$ ); The arrangement pattern is the same as in Figure 4.

\subsection{Key structural pathways of production-based carbon emissions of case}

\section{sectors}

The SPA approach is capable of uncovering where the production emissions from economic sectors have gone. In this section, the key pathways of Sector 22's (Electric Power, Steam and Hot Water Production and Supply) production-based carbon emissions from Inner Mongolia and Jiangsu are identified. This identification is necessary because these two provinces had the largest exported carbon emission ratios in 2010, and the electric sector accounted for more than 3/4 of their production-based 
carbon emissions, the highest among the 30 Chinese regions. Since the CG-MRIO has 8196 sectors in total, there are $8196^{t}$ paths of the $t$ th order for each pair of carbon emission source and destination. Under limited computing power, only the 25 top ranking paths from the T0-T3 tiers are identified, and infinite paths at higher tiers are ignored. According to the aforementioned results, this would not trigger deviations that are too large.

From the production perspective, the key carbon emission pathways originating from Sector 22 of Inner Mongolia (Sector 142 in CG-MRIO) and Jiangsu (Sector 292 in CG-MRIO) are shown in Table S3, SI (the full definition of abbreviations can be found in Table S2, SI). The sum of these pathways have, respectively, accounted for $24.62 \%$ and $18.94 \%$ of each sector's total production-based carbon emissions in 2010 . Among the 25 pathways, 11 paths from Sector 142 and 4 paths from Sector 292 ended in other provinces to meet other provinces' final demands, sharing $30 \%$ and $9 \%$ of the sum of carbon emissions embodied in the 25 top ranking pathways, respectively.

Since about a half of electricity industry's top 25 ranking carbon pathways ended in Jilin, Hebei, Tianjin, Beijing and Shandong, Inner Mongolia may reduce its electricity exports to these regions to efficiently reduce local territorial carbon emissions. With this reduction, Inner Mongolia may achieve its low-carbon goal without cutting its own demand. On the other hand, Jiangsu must focus more on its local final demand of electricity. Jiangsu can also increase its imports of products that rely heavily on the electricity industry to reduce its local carbon emissions. 


\subsection{Key structural pathways of consumption-based carbon emissions of case regions}

The SPA approach can also trace the origins of the emissions embodied in final products. As famous megacities, Beijing and Shanghai are the most developed regions in China. The key supply chains needed to meet their final demands are analyzed. Each Chinese province or city has two types of final demands: Total Final Consumption Expenditure (TFC) and Gross Capital Formation (GCF). They are traced individually in the present work. The 25 top ranking key carbon emission supply pathways of TFC in Beijing and Shanghai are respectively shown in Table S4, SI. Their sum accounted for $28.02 \%$ and $36.46 \%$ of Beijing and Shanghai's total carbon emissions embodied in the TFC, respectively. Therein, 11 paths of Beijing and 14 paths of Shanghai originated from other provinces, sharing $24 \%$ and $32 \%$ of the sum of carbon emissions embodied in the 25 top ranking pathways of TFC, respectively. Shanghai's TFC seems to rely slightly more on outer sources. The outsourced carbon emissions from the two megacities were, respectively, imported from 3 and 7 provinces, which indicated that the carbon emissions supply chains of Shanghai were more diverse.

With regard to the GCF (see Table S5, SI), the carbon emission sum from the top 25 paths accounted for $18.29 \%$ and $17.83 \%$, respectively, of Beijing and Shanghai's total embodied GCF carbon emissions in 2010. According to the results, Beijing's GCF relied more on outer sources compared to that of Shanghai. The sources of carbon emissions embodied in Beijing's GCF were slightly more diverse than those in 
its TFC but were still not as diverse as those of Shanghai. Similar to the TFC, the supply chain of Beijing's GCF was determined to be slightly longer than that of Shanghai’s GCF.

To reduce consumption-based carbon emissions without lowering living standards, the local government can substitute carbon-intensive imports with low-carbon products. For example, within the concerned 25 paths, nearly all of Beijing's outsourced TFC carbon emissions were imported from the electricity industry of Inner Mongolia and Shanxi. However, the electricity production of these two provinces had relatively higher direct carbon emission coefficients (ranked $4^{\text {th }}$ and $7^{\text {th }}$ among 30 Chinese provinces), i.e., $e$ in Eq. (8), compared to the other provinces. Therefore, Beijing is suggested to import more electricity products from nearby Hebei and Shandong, for which the direct carbon emission intensities were only $59 \%$ and $66 \%$ of that in Inner Mongolia, respectively.

\section{Conclusions}

China has demonstrated a strong determination to mitigate climate change by promising the world to reduce its carbon dioxide emissions intensity by $60 \%$ to $65 \%$ from 2005 levels by 2030. As regional differences in China are outstanding, the central government attributes varying carbon emission reduction goals to different Chinese regions. The present work analyzes both production and consumption-based carbon emissions of Chinese provinces and cities, which can be served as fundamental basis data to fairly and efficiently attribute regional quotas. Since the 
interconnections among Chinese regions are very close and intensive, the method of MRIO is relied on to trace carbon emissions along the supply chains. China is famous as the factory of the world, where international trade plays a very important role to fuel its economic growth. However, most previous MRIO studies of China have ignored foreign imports [47-49]. This work connects the Chinese MRIO model to Global MRIO tables to compile a China-global multi-regional input-output table (CGMRIO), which can complete the system boundary against a background of global economic integration.

Despite consumption-based carbon emissions of China have increased twice as fast as production-based carbon emissions from 2007 to 2010, overall consumption-based emissions in China is still 10\% lower than the production-based emissions in 2010. Less developed regions have experienced faster carbon emissions increase than rich regions during the accounting period in terms of both production-based and consumption-based carbon emissions. The carbon emissions embodied in domestic trade and foreign imported carbon emissions of China as a whole have increased by $16 \%$ and $52 \%$, respectively; yet the foreign exported carbon emissions have declined by $17 \%$. Meanwhile most Chinese provinces and cities exhibited significant increases in domestic exported, domestic imported, and foreign imported carbon emissions, but decreases in foreign exports. An indicator of the CII is formulated in this work in order to assess the carbon emissions imbalances of Chinese regions. It is revealed that the carbon emission imbalances of most Chinese regions, as well as China as a whole, have been reduced, but regional disparities in terms of per capita carbon emissions 
have widened between 2007 and 2010 .

The complex transmission chains from production-based carbon emissions to consumption-based carbon emissions of Chinese regions are investigated by the Structural Path Analysis (SPA) method for the first time in the present study. Most regions embodied the largest production-based and consumption-based carbon emissions in Tier 1. The ratios of both imported (to consumption-based) and exported (to production-based) carbon emissions in further upstream supplier tiers of most Chinese provinces and cities were higher than that of direct carbon emissions imports and exports in the first tier.

Based on SPA, case studies are then carried out to uncover the main pathways where the production emissions from economic sectors have gone and where the consumption emissions driven by final demand have come from for four typical regions. According to the results, one of the most effective measures for Inner Mongolia to lower its territorial carbon emissions is to reduce its electricity exports to Jilin, Hebei, Tianjin, Beijing and Shandong. And Beijing is suggested to import more electricity products from nearby Hebei and Shandong as their electricity industries have much lower direct carbon emission coefficients than Inner Mongolia and Shanxi.

\section{Acknowledgments}

This study was supported by the Natural Science Foundation of China (71503236, 41629501), the National Key R\&D Program of China (2016YFA0602604), Social Science Foundation of Beijing (16LJC013), the UK Economic and Social Research 
Council (ES/L016028/1), the UK Natural Environment Research Council

(NE/N00714X/1), and British Academy Grant (AF150310). Kuishuang Feng acknowledges the support of the National Natural Science Foundation of China (71628301).

\section{Supplementary material}

Additional materials as noted in the text.

\section{References}

[1] Doyle A, Lewis B. World seals landmark climate accord, marking turn from fossil fuels. Paris: Reuters; 2015.

[2] Department of Climate Change, National Development and Reform Commission, People's Republic of China. Enhanced actions on climate change: China's intended nationally determined contributions. Beijing; 2015. (In Chinese).

[3] Ji PJ, Ni T. Promoting concrete collaboration in low-carbon city development field. People's Daily. Beijing; 2016. (In Chinese).

[4] The Chinese Government. Key targets of China's 13th five-year plan. Xinhua; 2016. (In Chinese).

[5] The State Council of People's Republic of China. The Work Plan for Controlling Greenhouse Gas Emissions during the 12th Five-Year Plan Period. 2011. (In Chinese).

[6] The State Council of People's Republic of China. The Work Plan for Controlling 
Greenhouse Gas Emissions during the 13th Five-Year Plan Period. 2016. (In Chinese).

[7] National Development and Reform Commission, People's Republic of China. The energy reduction evaluation results of each province and city in 2014. http://qhs.ndrc.gov.cn/gzdt/201510/t20151013_754406.html. 2015. (In Chinese).

[8] National Development and Reform Commission, People's Republic of China. The energy reduction evaluation results of each province and city in 2013. http://qhs.ndrc.gov.cn/gzdt/201502/t20150215_664905.html. 2015. (In Chinese).

[9] Ye B, Jiang J, Li C, Miao L, Tang J. Quantification and driving force analysis of provincial-level carbon emissions in China. Appl Energ. 2017;198:223-38.

[10] Chen J, Cheng S, Song M, Wu Y. A carbon emissions reduction index: Integrating the volume and allocation of regional emissions. Appl Energ. 2016;184:1154-64.

[11] Su B, Ang BW. Input-output analysis of $\mathrm{CO} 2$ emissions embodied in trade: A multi-region model for China. Appl Energ. 2014;114:377-84.

[12] Chen S, Chen B. Tracking Inter-Regional Carbon Flows: A Hybrid Network Model. Environ Sci Technol. 2016;50(9):4731.

[13] Duan CC, Chen B. Inter-regional carbon flows of China. Appl Energ. In press. 2018.

[14] Liu Y, Chen S, Chen B, Yang W. Analysis of CO2 emissions embodied in China's bilateral trade: a non-competitive import input-output approach. J Clean Prod. 2017;163(Supplement):S410-9. 
[15] Feng KS, Davis SJ, Sun LX, Li X, Guan DB, Liu WD, et al. Outsourcing CO2 within China. P Natl Acad Sci USA. 2013;110(28):11654-9.

[16] Peters GP. From production-based to consumption-based national emission inventories. Ecol Econ. 2008;65(1):13-23.

[17] Brizga J, Feng K, Hubacek K. Household carbon footprints in the Baltic States: A global multi-regional input-output analysis from 1995 to 2011. Appl Energ. 2017;189:780-8.

[18] Feng KS, Hubacek K, Sun LX, Liu Z. Consumption-based CO2 accounting of China's megacities: The case of Beijing, Tianjin, Shanghai and Chongqing. Ecol Indic. 2014;47:26-31.

[19] Mi Z, Zhang Y, Guan D, Shan Y, Liu Z, Cong R, et al. Consumption-based emission accounting for Chinese cities. Appl Energ. 2016;184:1073-81.

[20] Shao L, Guan D, Zhang N, Shan Y, Chen GQ. Carbon emissions from fossil fuel consumption of Beijing in 2012. Environ Res Lett. 2016;11(11):114028.

[21] Guan D, Hubacek K, Weber CL, Peters GP, Reiner DM. The drivers of Chinese CO2 emissions from 1980 to 2030. Global Environ Change. 2008;18(4):626-34.

[22] Wiebe KS, Bruckner M, Giljum S, Lutz C, Polzin C. Carbon and Materials Embodied in the International Trade of Emerging Economies A Multiregional Input-Output Assessment of Trends Between 1995 and 2005. J Indust Ecolog. 2012;16(4):636-46.

[23] Su B, Ang BW. Multi-region input-output analysis of $\mathrm{CO} 2$ emissions embodied in trade: The feedback effects. Ecol Econ. 2011;71(0):42-53. 
[24] Zhang B, Yang TR, Chen B, Sun XD. China's regional CH4 emissions: Characteristics, interregional transfer and mitigation policies. Appl Energ. 2016;184:1184-95.

[25] Lenzen M, Pade L-L, Munksgaard J. CO2 Multipliers in Multi-region InputOutput Models. Econ Syst Res. 2004;16(4):391-412.

[26] Chen ZM, Chen GQ. Embodied carbon dioxide emission at supra-national scale: A coalition analysis for G7, BRIC, and the rest of the world. Energ Policy. 2011;39(5):2899-909.

[27] Peters GP, Hertwich EG. Structural analysis of international trade: Environmental impacts of Norway. Econ Syst Res. 2006;18(2):155-81.

[28] Skelton A. EU corporate action as a driver for global emissions abatement: A structural analysis of EU international supply chain carbon dioxide emissions. Global Environ Change. 2013;23(6):1795-806.

[29] Skelton A, Guan D, Peters GP, Crawford-Brown D. Mapping Flows of Embodied Emissions in the Global Production System. Environ Sci Technol. 2011;45(24):10516-23.

[30] Acquaye AA, Wiedmann T, Feng K, Crawford RH, Barrett J, Kuylenstierna J, et al. Identification of 'Carbon Hot-Spots' and Quantification of GHG Intensities in the Biodiesel Supply Chain Using Hybrid LCA and Structural Path Analysis. Environ Sci Technol. 2011;45(6):2471-8.

[31] Wood R, Lenzen M. Structural path decomposition. Energ Econ. 2009;31(3):33541. 
[32] Liu Z, Davis SJ, Feng K, Hubacek K, Liang S, Anadon LD, et al. Targeted opportunities to address the climate-trade dilemma in China. Nature Clim Change. 2016;6:201-6.

[33] Wiedmann T. A review of recent multi-region input-output models used for consumption-based emission and resource accounting. Ecol Econ. 2009;69(2):211-22.

[34] Wiedmann T, Lenzen M, Turner K, Barrett J. Examining the global environmental impact of regional consumption activities-Part 2: Review of input-output models for the assessment of environmental impacts embodied in trade. Ecol Econ. 2007;61(1):15-26.

[35] Davis SJ, Caldeira K. Consumption-based accounting of CO2 emissions. Proc Natl Acad Sci USA. 2010;107(12):5687.

[36] Leontief W. Quantitative input-output relations in the economic system. Econ Stat. 1936;18:105-25.

[37] Miller RE, Blair PD. Input-Output Analysis: Foundations and Extensions. 2nd ed. New York: Cambridge University Press; 2009.

[38] Leontief W. Input-output economics. 2nd ed. Oxford: Oxford University Press; 1986.

[39] Liu WD, Chen J, Tang ZP, Liu HG, Han D, Li FY. Theories and practice of constructing China's interregional input-output tables between 30 provinces in 2007. Beijing: Chinese Statistics Press; 2012. (In Chinese).

[40] Project GTA. Global Trade Analysis Project. GTAP 9 Data Base. 2015. 
[41] Project GTA. Global Trade Analysis Project. GTAP 8 Data Base. 2012.

[42] The United Nations Statistic Division (UNSD). National Accounts Main Aggregates Database-Implicit Price Deflators in National currency and US Dollars. 2015.

[43] Y. Shan, D. Guan, H.R. Zheng, J.M. Ou, Y. Li, J. Meng, et al., China CO2 emission accounts 1997-2015, Sci Data 5, 2018, 170201.

[44] China Statistical Yearbook $(2008,2011)$. Each province's Statistical Yearbook (2008, 2011). Beijing: China Statistical Publishing House. (In Chinese).

[45] Second National Economic Census Leading Office of the State Council of China. China Economic Census Yearbook 2008. Beijing: China Statistic Press; 2010. (In Chinese).

[46] Liu Z, Guan D, Wei W, Davis SJ, Ciais P, Bai J, et al. Reduced carbon emission estimates from fossil fuel combustion and cement production in China. Nature. 2015;524(7565):335-8.

[47] Zhang B, Qiao H, Chen ZM, Chen B. Growth in embodied energy transfers via China's domestic trade: Evidence from multi-regional input-output analysis. Appl Energ. 2016;184:1093-105.

[48] Tian X, Chang M, Lin C, Tanikawa H. China's carbon footprint: A regional perspective on the effect of transitions in consumption and production patterns. Appl Energ. 2014;123:19-28.

[49] Liu HG, Liu WD, Fan XM, Zou W. Carbon emissions embodied in demandsupply chains in China. Energ Econ. 2015;50:294-305. 
